\title{
Understanding of Cyclic Volatile Methyl Siloxane Fate in a High Latitude Lake Is Constrained by Uncertainty in Organic Carbon- Water Partitioning
}

Ingjerd Sunde Krogseth, ${ }^{*}{ }^{\dagger} \odot$ Michael John Whelan, ${ }^{\ddagger}$ Guttorm Normann Christensen, ${ }^{\S}$ Knut Breivik, ${ }^{\|, \perp}$ Anita Evenset, ${ }^{\S}$ and Nicholas Alexander Warner ${ }^{\dagger}$

${ }^{\dagger}$ NILU - Norwegian Institute for Air Research, The Fram Centre, P.O. Box 6606 Langnes, 9296 Tromsø, Norway

${ }^{*}$ Department of Geography, University of Leicester, Leicester LE1 7RH, United Kingdom

${ }^{\S}$ Akvaplan-niva AS, The Fram Centre, P.O. Box 6606 Langnes, 9296 Tromsø, Norway

"NILU - Norwegian Institute for Air Research, P.O. Box 100, 2027 Kjeller, Norway

${ }^{\perp}$ Department of Chemistry, University of Oslo, P.O. Box 1033, Blindern, 0315 Oslo, Norway

Supporting Information

\begin{abstract}
Cyclic volatile methyl siloxanes (cVMS) are emitted to aquatic environments with wastewater effluents. Here, we evaluate the environmental behavior of three cVMS compounds (octamethylcyclotetrasiloxane (D4), decamethylcyclopentasiloxane (D5) and dodecamethylcyclohexasiloxane (D6)) in a high latitude lake (Storvannet, $70^{\circ} \mathrm{N} 23^{\circ} \mathrm{E}$ ), experiencing intermittent wastewater emissions and high latitude environmental conditions (low temperatures and seasonal ice cover). Measured cVMS concentrations in lake water were below detection limits in both March and June 2014. However, mean concentrations in sediments were $207 \pm 30,3775 \pm$ 973 and $848 \pm 211 \mathrm{ng} \mathrm{g}^{-1}$ organic carbon for D4, D5 and D6, respectively. To rationalize measurements, a fugacity-based model for lakes (QWASI) was parametrized for Storvannet. The key removal

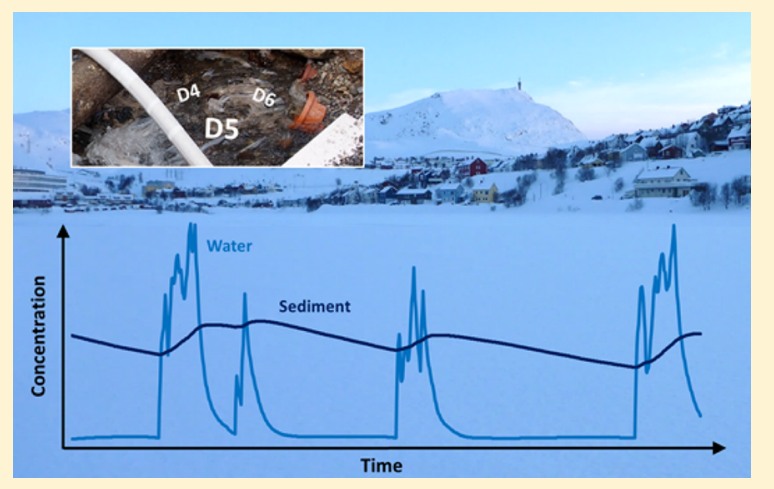
process for cVMS from the lake was predicted to be advection due to the low hydraulic retention time of the lake, followed by volatilization. Predicted cVMS behavior was highly sensitive to the partition coefficient between organic carbon and water $\left(K_{\mathrm{OC}}\right)$ and its temperature dependence. Predictions indicated lower overall persistence with decreasing temperature due to enhanced partitioning from sediments to water. Inverse modeling to predict steady-state emissions from cVMS concentrations in sediment provided unrealistically high emissions, when evaluated against measured concentrations in sewage. However, high concentrations of cVMS in sediment and low concentrations in water could be explained via a hypothetical dynamic emission scenario consistent with combined sewer overflows. The study illustrates the importance of considering compound-specific behavior of emerging contaminants that may differ from legacy organic contaminants.
\end{abstract}

\section{INTRODUCTION}

Cyclic volatile methyl siloxanes (cVMS) are used in polymer production, personal care products (PCPs) and various technical applications. ${ }^{1-3}$ The majority of environmental emissions arise from use of PCPs. Of the three compounds octamethylcyclotetrasiloxane (D4), decamethylcyclopentasiloxane (D5) and dodecamethylcyclohexasiloxane (D6), D4 and D6 are used in much lesser quantities than D5 which is most heavily used in PCPs. ${ }^{4}$ Although removal is efficient (95-99\%) in wastewater treatment plants (WWTPs), ${ }^{5-7}$ a fraction is also emitted to aquatic environments. ${ }^{1-3}$ There are currently no regulations for use of cVMS, but D4 and D5 were recently classified as very persistent and very bioaccumulative ( $\mathrm{vPvB})$ by the European Chemicals Agency ${ }^{8}$ and restrictions for inclusion in wash-off products have been proposed. ${ }^{9}$ Relatively high concentrations of cVMS have been measured in sediment and biota in aquatic environments close to populated areas. ${ }^{10,11}$ This can be explained by their hydrophobicity, favoring partitioning to organic matrices, combined with high usage and emissions. Aquatic environments with low emissions of proximal wastewater effluents have shown low or nondetectable concentrations of cVMS. ${ }^{12,13}$ However, many sparsely populated areas (including small communities at high latitudes) have poor wastewater treatment, resulting in direct discharge and potentially high local exposure to down-the-drain chemicals. $^{14,15}$ Additionally, there is a need to understand how

Received: September 23, 2016

Revised: November 29, 2016

Accepted: December 6, 2016

Published: December 6, 2016 


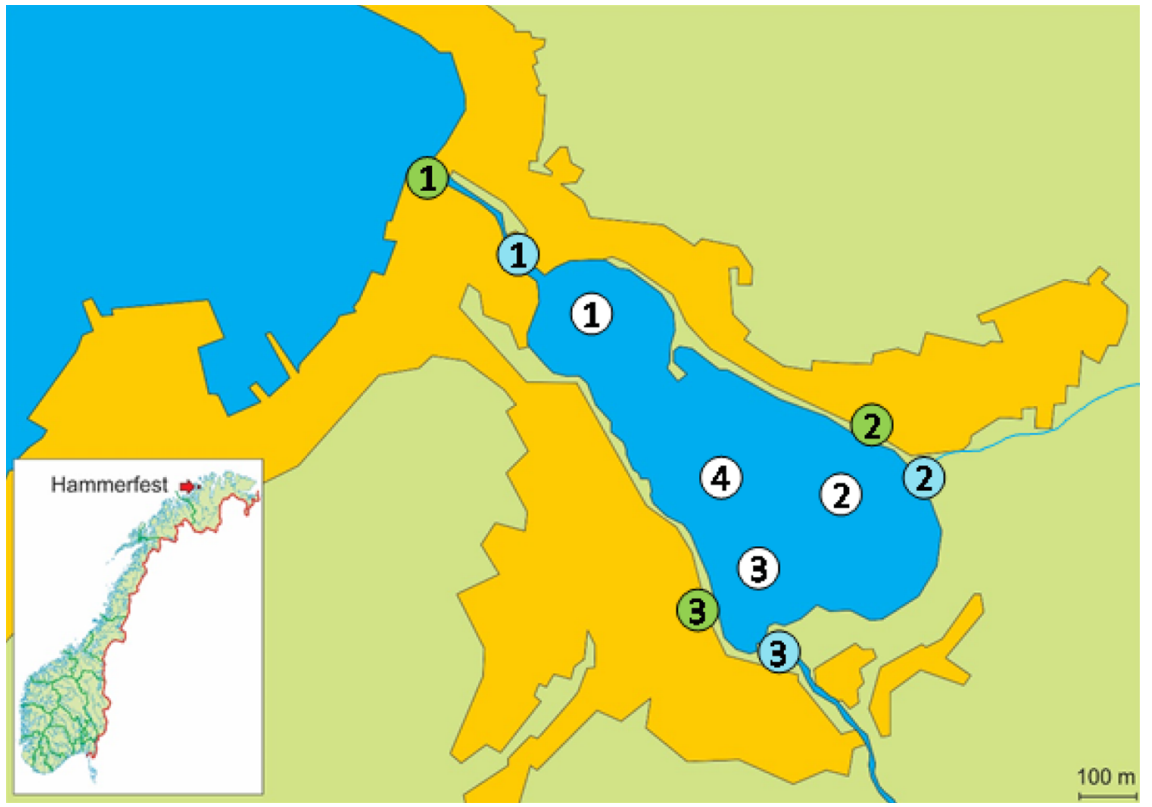

Figure 1. Sampling sites in and around Storvannet for lake water and sediment (white), river water (blue) and sewage (green). Yellow areas of the map indicate populated areas. The embedded map shows the location of Hammerfest in Norway.

environmental conditions at these latitudes (e.g., low temperatures and ice cover) influence cVMS behavior.

Models can complement monitoring studies for organic contaminants by embodying our conceptual understanding of system behavior and helping us to identify knowledge gaps. Several monitoring ${ }^{11,12,14}$ and modeling ${ }^{16-19}$ studies have been reported for cVMS in aquatic environments, but few have compared model predictions with measurements for a specific environment. Predictions from a dynamic fugacity-based multimedia model agreed well with observed cVMS concentrations in sediment from the Inner Oslofjord, despite high uncertainty in emissions. ${ }^{20}$ Behavior of cVMS in aquatic environments is generally controlled by advection, hydrolysis, volatilization and sediment burial, depending on the compound and the environmental characteristics. ${ }^{18,20}$ These processes can be affected by flow rates, water volume and depth, fluxes of organic matter and temperatures. In addition, seasonal ice cover was important for predicted concentrations of D5 in the Baltic Sea. ${ }^{19}$ Under a hypothetical scenario of complete emission cessation, overall (global) persistence of cVMS was predicted to be controlled by dissipation from sediment to water followed by hydrolysis, with overall half-lives of $1-2$ years for D5. ${ }^{21}$ This stresses the importance of understanding the behavior and persistence of cVMS in sediments and the interactions between the water and sediment compartments.

Here, we investigate the occurrence and behavior of cVMS in a high latitude lake (Storvannet, $70^{\circ} \mathrm{N} 23^{\circ} \mathrm{E}$ ). This lake was chosen because (i) cVMS contamination was expected as it receives emissions of raw sewage through leaks and combined sewer overflows (CSOs), (ii) the lake is relatively well-studied from investigations on native Arctic Char (Salvelinus alpinus) populations $^{22}$ and persistent organic pollutants (POPs) from local sources $^{23}$ and (iii) it is located in a high latitude environment with low temperatures and seasonal ice cover providing an opportunity to study the behavior of cVMS under these conditions. In addition, this study provides a baseline to assess persistence of cVMS in sediment, as emissions will cease in the near future with renovations of the local sewer system.
Fugacity-based multimedia modeling ${ }^{24-26}$ is used as a mechanistic framework in combination with measurements to understand the behavior of cVMS in this lake and to explore the influence of physicochemical properties, environmental characteristics, and steady-state vs dynamic assumptions.

\section{MATERIALS AND METHODS}

2.1. Study Site. Storvannet is located in a residential area of the town of Hammerfest in Northern Norway (Figure 1). It is a small $\left(0.2 \mathrm{~km}^{2}\right.$, maximum depth $\left.17 \mathrm{~m}\right)$ oligotrophic, nonstratified lake located $8 \mathrm{~m}$ above sea level (Supporting Information (SI) Table S10). According to the local municipality, the town had 7225 inhabitants in 2015, of which 3563 live around Storvannet (70\% on the Southwest side and $30 \%$ on the Northeast side). The lake has two inflowing rivers and one outflow to the nearby marine harbor. The residence time of the lake is about 9 days in summer and 38 days in winter. ${ }^{27}$ The lake is ice covered for approximately 6 months of the year; often from November to early June. There is no wastewater treatment in Hammerfest. Untreated sewage from the population around Storvannet was emitted to the lake through an underwater diffuser (Site 4, Figure 1) until the early 1970s, when the wastewater outfall was moved to the harbor. Currently, a combined sewer system collecting both sewage and surface runoff runs along both sides of the lake. Even if no wastewater is intentionally emitted to the lake, unintentional emissions to the lake occur through leaking pipes and CSOs, especially during periods with high water flow such as snowmelt season and heavy rainfall. Hence, the amount of wastewater actually emitted to Storvannet is unknown.

2.2. Sample Collection. Sampling was carried out in 2014; March 19-21 when the lake was ice covered (ice thickness 60$80 \mathrm{~cm}$ ) and June 23-25 when the lake was ice-free. To assess spatial variability, samples were collected from four sites within the lake (water and sediment) and three sites around the lakeshore (river water and sewage) (Figure 1, SI Tables S1S2). All sampling equipment was cleaned thoroughly before use (SI 1.1), and PCPs were avoided by personnel handling the 
samples. In winter, a manual ice drill was used to make holes in the ice to carry out the sampling.

Lake water was collected at $3 \mathrm{~m}$ depth with a Ruttner $2.0 \mathrm{~L}$ water sampler, and transferred to Duran glass bottles (250 or $500 \mathrm{~mL}$ ) filled completely to avoid any headspace. River water samples were collected by immersing a glass bottle under the water surface. Immediately after retrieving the samples, six aliquots of $15 \mathrm{~mL}$ water were transferred into $22 \mathrm{~mL}$ headspace vials (Teledyne Tekmar) and $10 \mu \mathrm{L}$ internal standard in acetone $\left(82 \mathrm{ng} \mathrm{mL}^{-113} \mathrm{C}_{4}\right.$-D4, $104 \mathrm{ng} \mathrm{mL}^{-1}{ }^{13} \mathrm{C}_{5}$-D5 and 112 $\mathrm{ng} \mathrm{mL}{ }^{-113} \mathrm{C}_{6}$-D6) was added to each vial (SI 1.1). ${ }^{28}$ Vials were capped with polytetrafluoroethylene (PTFE) lined butyl rubber septa (Agilent technologies) and aluminum crimp caps (SUN Sri). Sewage was collected from three sites at three different times $(08: 00,12: 00$ and 17:00) at June 25th to evaluate spatial and diurnal variability. All samples were collected by immersing a $500 \mathrm{~mL}$ Duran glass bottle into the wastewater stream, and closing it without any headspace. Sediment samples from the lake were collected with a gravity corer $(80 \mathrm{~mm}$ inner diameter (I.D.) in March, $45 \mathrm{~mm}$ I.D. in June). The top $1 \mathrm{~cm}$ of each sediment core was transferred to a glass jar. All samples were transported refrigerated, and water and sewage samples were prepared and analyzed immediately, while sediment was stored at $-20{ }^{\circ} \mathrm{C}$ until sample preparation.

Field blanks of sediment from Sanford Lake (Midland, MI, May 10th 2012, provided by Dow Corning Corporation) and bottled mineral water were brought to the field. Water field blanks were treated in the same way as regular water samples. Sediment field blanks were exposed during sediment sampling, and aliquots of the same material were kept in the laboratory freezer for comparison (hereafter named the reference sediment). The $\mathrm{pH}$ of the water samples was determined in the laboratory using a WTW pH 3110 meter (SI Table S1). Aliquots of sediment samples were shipped to ALS Denmark $\mathrm{A} / \mathrm{S}$ for determination of dry weight $(\mathrm{dw})$ and total organic carbon (TOC) content (accredited method DS/EN ISO 13137) (SI Table S2).

2.3. Extraction and Analysis of cVMS. Prior to analysis, aliquots of $15 \mathrm{~mL}$ sewage samples were prepared in the lab the day after sample collection in the same way as water samples had been prepared in the field (section 2.2). Water and sewage samples were subjected to static headspace analysis based on the method of Sparham et al. ${ }^{28}$ (all details in SI 1.2.1). All samples were within calibration curve range except for one sewage sample (site 3, 08:00), which was diluted 1:10 v:v sewage:bottled mineral water to reduce the concentration to within the calibration curve range. Sediment samples were extracted with a biphasic cold solvent extraction, adapted from Sparham et al. ${ }^{29}$ (all details provided in SI 1.2.2). Extracts were analyzed using a concurrent solvent recondensation large volume injection (CSR-LVI) technique (SI 1.2.2). ${ }^{30-32}$

Limits of detection (LOD) and quantification (LOQ) for cVMS in water and sewage samples were calculated as the average concentration in field blanks plus three and ten times the field blank standard deviation, respectively. For sediment samples, LODs and LOQs were calculated the same way using procedural (n-hexane) blank samples. As average concentrations in blank samples were incorporated into LODs and LOQs, sample results were not blank-corrected. For sediment samples, the method detection limit (MDL, SI 1.4) ${ }^{33}$ was calculated for comparison to LOQ. Results were not corrected for the purity of the internal standards.
2.4. Modeling of Physical Transport and Fate. To model cVMS in Storvannet, a modification of the fugacitybased multimedia lake model QWASI by Mackay et al. ${ }^{34}$ was used. This model simulates exchange processes between air, water, and sediment, as well as transformation processes within these media. ${ }^{25,34}$ Two model versions were applied: (i) a steady-state version consistent with QWASI v2.8, with modifications, ${ }^{18}$ and (ii) a dynamic version allowing for temporal changes in temperature, water flows, ice cover and emissions. The models consist of one water and one sediment compartment assuming these are homogeneous and well mixed. Previous dynamic developments of the QWASI model ${ }^{20,35}$ have allowed annual changes in emissions, and seasonal changes in environmental conditions, but not episodic emission events. Here, daily fluctuations in emissions, water temperature and river inflow were incorporated. The mass balance equations for water and sediment (SI 1.8) were solved numerically using Euler's method ( $1 \mathrm{~h}$ time step).

Model parametrization was based on information about dimensions, hydrology and meteorology of the lake and its catchment $^{22,27,36-40}$ as well as measurements from Storvannet in 2014 (SI 1.5, Table S10). The steady-state model was run for four temperature scenarios: (i) $0{ }^{\circ} \mathrm{C}$ (winter); (ii) $3.5{ }^{\circ} \mathrm{C}$ (average); (iii) $8{ }^{\circ} \mathrm{C}$ (summer) and (iv) $0{ }^{\circ} \mathrm{C}$ with air-water exchange turned off (representing ice cover). In all scenarios, an average water flow was assumed (and inflow was assumed equal to the outflow) (Table S10). In the dynamic model, daily resolved air temperatures, water flow data and ice cover were used as input (SI 1.5).

Physicochemical properties for cVMS were based on experimental data (SI 1.6, Table S12). Hydrolysis was assumed to occur in the aqueous phase only (i.e., not for cVMS sorbed to particles). ${ }^{1,2,21}$ Degradation $^{18,20}$ and partitioning properties were temperature-adjusted in the steady-state scenarios and on a daily basis in the dynamic model. Several values have been reported for cVMS partition coefficients between organic carbon $(\mathrm{OC})$ and water $\left(K_{\mathrm{OC}}\right)^{41-44}$ and between octanol and water $\left(K_{\mathrm{OW}}\right){ }^{45,46}$ Some data have also been reported for the temperature dependence of $K_{\mathrm{OW}}$ (the enthalpy of phase change, $\left.\Delta U_{\mathrm{OW}}\right)^{47,48}$ (SI Table S12, Figure S3). However, measured data for the temperature dependence of $K_{\mathrm{OC}}$ has not yet been reported. The value for $\Delta U_{\mathrm{OC}}$ was, therefore, assumed equal to $\Delta U_{\mathrm{OW}}$, but the limitation of this is acknowledged. Baseline model simulations were run with $\log K_{\mathrm{OC}} \mathrm{s}=4.2$ and 5.2 for D4 and D5, ${ }^{45}$ respectively, and $\Delta U_{\mathrm{OW}} \mathrm{s}=7.9$ and $29 \mathrm{~kJ}$ $\mathrm{mol}^{-1}$ for D4 and D5, respectively, ${ }^{48}$ in accordance with previous model simulations. ${ }^{18-20}$ The older $\Delta U_{\mathrm{OW}} \mathrm{s}^{48}$ were used rather than the more recent ones ${ }^{45,47}$ as they provided results in better agreement with measurements (section 3.2). However, for evaluation, simulations (including sensitivity analysis) were also run with the most recent $\Delta U_{\mathrm{OW}} \mathrm{s}$ of 31.9 and $68.8 \mathrm{~kJ} \mathrm{~mol}^{-1}$ for D4 and D5, respectively. ${ }^{45,47}$

All input of cVMS was assumed to occur via untreated discharge directly to lake water. Concentrations in inflowing rivers were set to zero, and concentrations in air assumed consistent with measurements from Nordic background sites (SI Table S12). ${ }^{49,50}$ However, model predictions are insensitive to concentrations in air for cVMS due to very high water to air fugacity gradients. ${ }^{18}$ The steady-state mass-balance equations in QWASI were rearranged to yield predicted emissions, given a concentration in sediment (SI 1.8). The targeted cVMS concentrations in sediment were the mean of the measured concentrations (ng $\mathrm{g}^{-1}$ OC) normalized to the measured 

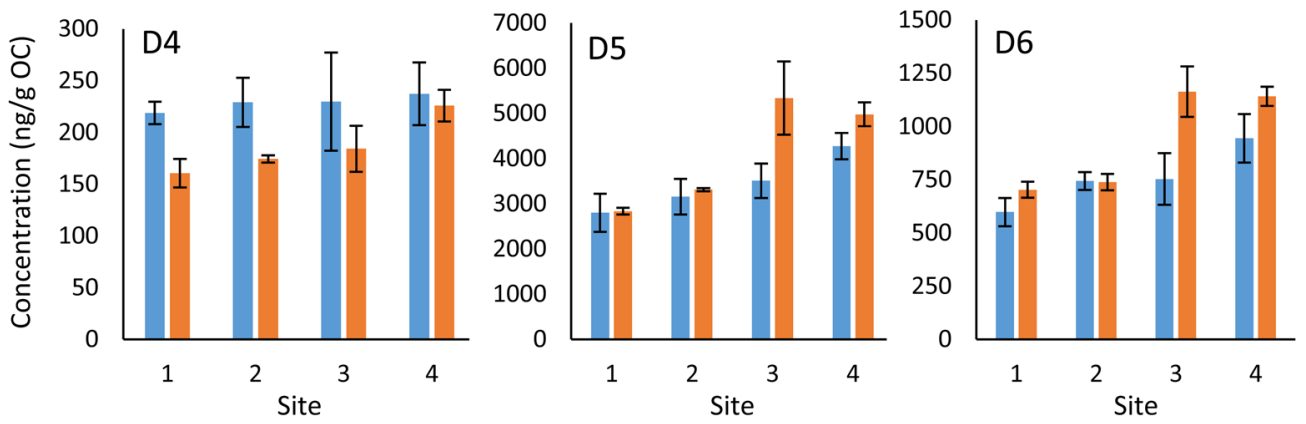

Figure 2. Concentrations of D4, D5, and D6 in surface sediments of Storvannet ( $\mathrm{ng} \mathrm{g}^{-1}$ OC) in March (blue) and June (orange) represented as the average and standard deviation (error bars) of triplicate samples.

average fraction of OC $\left(f_{\mathrm{OC}}=5 \%\right)$ (SI Table S12). For comparison purposes, per capita emission estimates of cVMS to wastewater for the UK $\mathrm{UK}^{1-3,5,51}$ were used to estimate emissions from the population around Storvannet (SI 1.9). Note that predicted persistence and main elimination processes from QWASI are independent of emissions.

A sensitivity analysis was conducted with the steady-state model for selected environmental and physicochemical properties for which uncertainty was highest (SI Table S10, S12). System dimensions and flow rates were assumed to be wellknown. Parameters were varied in steps of $\pm 5 \%$, with other parameters held at their default values, and effects on predicted concentration in water and sediment recorded. Water temperature of $3.5^{\circ} \mathrm{C}$ and constant emissions derived from the inverse modeling were assumed.

In reality, emissions to Storvannet are not constant, as assumed in the steady-state model. A hypothetical dynamic emission scenario was constructed to simulate intermittent leaks and CSOs (SI 1.7) with the principal intention of evaluating the plausibility of this scenario as an explanation for the observed concentrations. Emissions were assumed to be a hypothetical function of catchment runoff as CSOs are known to be related to high water flow events (section 2.1). ${ }^{37}$

\section{RESULTS AND DISCUSSION}

3.1. Measured Concentrations of cVMS. 3.1.1. Sewage. All LODs, LOQs, and recoveries are reported in (SI 1.3, Table S3-S5). D5 was the dominant cVMS in sewage and was above LOQ in all samples $(n=8)$, while D4 and D6 were only above LOQ in 3 and 2 individual samples, respectively (SI Table S6). This is consistent with other reported results in sewage and known emission profiles of cVMS where D5 is dominant, followed by D6 and D4.,6,52 Large variation in D5 concentrations was observed between sites and sampling times, ranging from $23.2 \mathrm{ng} \mathrm{L}^{-1}$ (St2, 08:00) to $1415 \mathrm{ng} \mathrm{L}^{-1}$ (St3, 08:00). Site 2 generally displayed lower concentrations than the other sites, probably due to the lower population on this side of the lake. Highest concentrations were observed in the morning (8:00 am) at site 3 for D4 and D5 and at site 1 for D6. Diurnal variation of cVMS concentrations in sewage has been reported in the UK with peak concentrations in the morning and a second peak in the evening. ${ }^{5}$ Overall, concentrations of cVMS in the untreated sewage in Hammerfest were more comparable to concentrations in WWTP effluent than influent reported from urban areas in Europe and North America. ${ }^{5,6,10,28,52,53}$ This could be explained by a combination of lower usage rates and higher dilution in the combined sewer system. Despite measures to limit loss of
cVMS from the sewage samples through hydrolysis and/or volatilization during storage and transport (refrigerated bottles with no headspace for maximum $24 \mathrm{~h}$ ), it is acknowledged that some loss of cVMS may have occurred prior to preparation of samples in headspace vials, ${ }^{5,28,54}$ resulting in slightly underestimated concentrations.

3.1.2. Water. All cVMS concentrations in lake water were below LOD or LOQ, except for D4 in a single replicate of river water (although this was still below the highest concentrations measured in an individual field blank). Hence, these results are not reported and concentrations of cVMS in lake water remain unknown. Few measured concentrations of cVMS in environmental water samples are available in the literature and they were not found above detection limits in water from the Oslofjord. ${ }^{53}$ This is partly due to difficulties in measuring these compounds at trace levels in water. ${ }^{28,55}$

3.1.3. Surface Sediments. As LOQs were higher than MDLs, LOQs were used as a conservative quantification limit (SI 1.3, 1.4, SI Table S4). All cVMS compounds were above LOQ in all sediment samples (Figure 2, SI Tables S7-S9). The mass of cVMS in the samples were 2-13, 150-2150, and 10170 times the average mass of cVMS in the procedural blanks for D4, D5, and D6, respectively. As results were not blankcorrected, D4 concentrations could be slightly overestimated due to the relatively low ratio between the mass of D4 in samples and blanks. D5 dominated in all samples, followed by D6 and then D4. Average concentrations of D4, D5, and D6 were $4.4 \pm 1.2,66.2 \pm 22.7$, and $14.6 \pm 4.8 \mathrm{ng} \mathrm{g}^{-1}$ ww in March $\left(229 \pm 8,3435 \pm 631\right.$ and $759 \pm 142 \mathrm{ng} \mathrm{g}^{-1}$ OC), and $3.9 \pm$ $0.2,86.5 \pm 8.2$ and $19.6 \pm 1.0 \mathrm{ng} \mathrm{g}^{-1}$ ww in June $(186 \pm 8$, $4115 \pm 358$ and $937 \pm 40 \mathrm{ng} \mathrm{g}^{-1}$ OC), respectively. The dry weight content was higher and the OC content lower at site 2 than at the other sites (SI Table S2), and the remainder of the discussion is based on OC-normalized concentrations (Figure 2).

To test for significant differences between samples, F-test and $t$ test statistics were used as for field blanks (SI 1.1). In June, concentrations of D5 and D6 were significantly higher at sites 3 and 4 than at sites 1 and 2 (D5: $p=0.0002-0.04$, D6: $p$ $=0.0002-0.02)$. Concentrations were also significantly higher for D5 and D6 at sites 3 and 4 in June than in March ( $p=$ $0.01-0.05)$. CSOs were reported in the southern corner of the lake in May, and deposits from these events may explain the higher concentrations at sites 3 and 4 in June. Considering all sites, there were no statistically significant differences in cVMS concentrations in sediments between March and June on either a ng $\mathrm{g}^{-1} \mathrm{ww}, \mathrm{ng} \mathrm{g}^{-1} \mathrm{dw}$ or $\mathrm{ng} \mathrm{g}^{-1}$ OC basis $(p>0.05)$. 
Concentrations of D5 in Storvannet sediments ( $\mathrm{ng} \mathrm{g}^{-1} \mathrm{OC}$ ) are comparable to sediments in other aquatic systems receiving wastewater effluents, such as Swedish and South-Norwegian lakes, ${ }^{12,52}$ the Humber Estuary ${ }^{11,29}$ and Lake Pepin, ${ }^{56}$ but lower than in the Inner Oslofjord ${ }^{57}$ and the River Ouse, ${ }^{11,29}$ and higher than in the Outer Oslofjord ${ }^{57}$ and in an Arctic fjord. ${ }^{14}$ The ratio of D6 to D4 in Storvannet sediments (ratio of 3-6) is lower than that reported in other systems with comparable D5 concentrations (often ratios of 10-40). ${ }^{11,52,56,57}$ This could indicate a different emission profile (current or historical), possibly influenced by the lack of wastewater treatment, and/or a different behavior of cVMS in Storvannet compared to other aquatic environments.

3.2. Model Predictions and Evaluation. 3.2.1. SteadyState Baseline Scenario for Storvannet. In the average temperature scenario $\left(3.5{ }^{\circ} \mathrm{C}\right)$ and assuming $\Delta U_{\mathrm{OW}}=7.9$ and $29 \mathrm{~kJ} \mathrm{~mol}^{-1}$ for D4 and D5, respectively, removal of cVMS from Storvannet was dominated by advection from the water column (63-74\% of loss), followed by volatilization (23-28\% of loss) (Figure 3, SI Table S13). This is due to the short

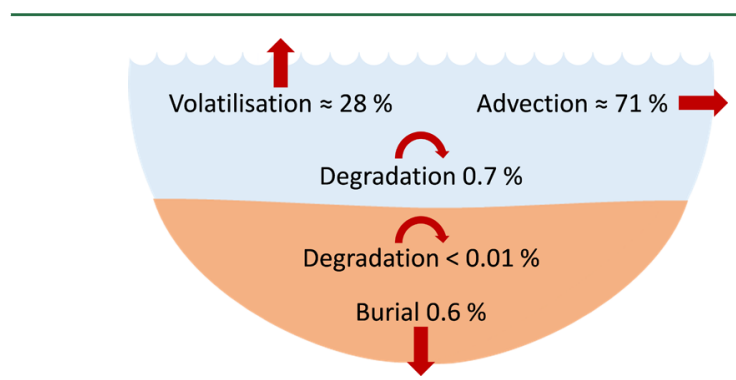

Figure 3. Illustration of the mass-balance of D5 in the average baseline scenario under steady-state, assuming $\Delta \mathrm{U}_{\mathrm{OW}}=29 \mathrm{~kJ} \mathrm{~mol}^{-1}$.

hydraulic residence time in Storvannet (average 16 days) compared with half-lives of other loss processes. Hydrolysis slows down at low temperatures and sediment burial is limited by a low sediment deposition rate (ca. $2 \mathrm{~mm} \mathrm{y}^{-1}$, SI Table S10). Hence, degradation in water was only important for D4, while degradation in sediment was negligible for all compounds, and burial only accounted for up to $3.2 \%$ of total loss (D6). In other systems, volatilization (D6 in Lake Ontario, D5 and D6 in Oslofjord), burial (D6 in Lake Pepin) and hydrolysis (D4 and D5 in Lake Ontario; D4 in Lake Pepin and Oslofjord) have been predicted to dominate, ${ }^{18,20}$ while advection was predicted to dominate for D5 in Lake Pepin. ${ }^{17,18}$ Dominance of advection in Storvannet means that predicted persistence (or chemical residence time, defined as half-life/ $\ln (2)$ ) does not differ as much between cVMS compounds as in other systems. ${ }^{18}$ For all cVMS, persistence in water $\left(P_{\mathrm{W}}\right)$ was $10-12$ days and persistence in sediment $\left(P_{S}\right)$ 6.2-6.6 years (SI Table S13). The latter was controlled by sediment burial rather than degradation in sediments or desorption from sediments. Differences in the combined overall persistence $\left(P_{\mathrm{OV}}\right)$ (1389 days) reflect partitioning between water and sediment for the three compounds, with longest $P_{\mathrm{OV}}$ for D6 (SI Table S13). This is comparable to Lake Pepin, but shorter compared to Lake Ontario (except for D4, which hydrolyzes quickly in these warmer systems). ${ }^{18}$ However, these residence times for Lake Pepin and Lake Ontario are shorter than those calculated by Mackay et al., ${ }^{17}$ due to an assumed lower active sediment layer depth, which is directly proportional to sediment residence time.
Inverse-modeled steady-state emissions of $1.2,4.7$, and $0.2 \mathrm{~kg}$ $\mathrm{y}^{-1}$ were required to match mean measured concentrations in sediment of 10, 189, and $42 \mathrm{ng} \mathrm{g}^{-1} \mathrm{dw}$ for D4, D5 and D6, respectively, at the average lake temperature (SI Table S13). The corresponding predicted concentrations in water were 16 , 67, and $3 \mathrm{ng} \mathrm{L}^{-1}$ for D4, D5 and D6, respectively (SI Table S13). These are below our LOQs for D4 and D6, but exceed the LOQ for D5, although D5 was not detected in lake water (SI Table S3, section 3.1.2). Compared to emission estimates derived using the population around Storvannet and per capita cVMS emissions to wastewater from the UK $(0.12,3.5$, and 0.4 $\mathrm{kg} \mathrm{y}^{-1}$ for D4, D5 and D6, respectively: SI 1.9), the emission estimates from the inverse modeling are 10 times higher for D4, but similar (factor differences of 1.3 and 0.5 , respectively) for D5 and D6. However, only a fraction of the total cVMS in sewage is expected to go to Storvannet (most will flow to the main outlet in the harbor), and untreated wastewater concentrations derived from these emissions (90-450, 280013700 , and $320-1600 \mathrm{ng} \mathrm{L}^{-1}$ for D4, D5, and D6; SI 1.9) are a minimum of 2-3 times higher than observed in the Storvannet sewers. If we assume the highest measured cVMS concentrations in sewage $\left(52,1415\right.$, and $100 \mathrm{ng} \mathrm{L}^{-1}$ for D4, D5, and D6, respectively, SI Table S6), steady-state wastewater losses to the lake of $230-2850 \mathrm{~m}^{3} \mathrm{~h}^{-1}$ would be required to achieve the inverse-modeled emissions. This is inconsistent with our current knowledge about sewage discharge and leakage rates (total flow from 7225 people is ca. $60 \mathrm{~m}^{3} \mathrm{~h}^{-1}$ assuming $200 \mathrm{~L}$ cap $^{-1} \mathrm{~d}^{-1}$ ). A possible underestimation of $\mathrm{cVMS}$ concentrations in sewage due to losses during storage for $24 \mathrm{~h}$ cannot account for this deviation.

3.2.2. The Impact of Physicochemical Properties in Cold Lakes. Predicted cVMS concentrations in sediment were most sensitive to $K_{\mathrm{OC}}$ and $\Delta U_{\mathrm{OW}}$ and (consequently) to $f_{\mathrm{OC}}$ in sediment, the sediment deposition rate and $f_{\mathrm{OC}}$ in suspended material (SI Figure S4-S9). Due to higher importance of hydrolysis for D4 than for the other compounds, D4 in sediment was also sensitive to the temperature dependence of hydrolysis (Arrhenius activation energy, $E_{\mathrm{A}}$ ) (SI Figure S7). Predicted cVMS concentrations in water were much less sensitive to chemical-specific parameters than concentrations in sediment (SI Figures S4, S6, S8, S9). They were most sensitive to the mass transfer coefficients at the air-water interface that control volatilization. Notably, predicted concentrations of D4 and D5 in sediment were two and three times lower, respectively, at $3.5{ }^{\circ} \mathrm{C}$ when the higher value for $\Delta U_{\text {OW }}$ (i.e., the most recently reported experimental value of this parameter ${ }^{45,47}$ ) was used (SI Figures S4-S7). As the temperature in Storvannet is low $\left(0-1{ }^{\circ} \mathrm{C}\right.$ for 8 months of the year: SI Table S11, SI Figure S1), ${ }^{40}$ the effect of temperature, $K_{\mathrm{OC}}$ and $\Delta U_{\mathrm{OW}}$ for the predicted behavior of cVMS merits more detailed discussion (for Storvannet and beyond).

While many organic compounds have negative $\Delta U_{\mathrm{OW}}$ values (e.g., -19 to $-27.5 \mathrm{~kJ} \mathrm{~mol}^{-1}$ for PCBs), ${ }^{58}$ implying increased partitioning to organic matter at lower temperatures, cVMS have positive $\Delta U_{\mathrm{OW}}$ values (SI Table S12) predicting increased partitioning to water at lower temperatures (Figure 4, SI Figure S3). This means that the expectation of decreased cVMS persistence at higher temperatures (due to increased hydrolysis rates) may be counteracted by a decrease in the dissolved phase fraction. In the steady-state scenarios, predicted loss through degradation in water increased with increasing temperature for D4 (with a concurrent decrease in $P_{\mathrm{W}}$ and $P_{\mathrm{S}}$ ), but remained 


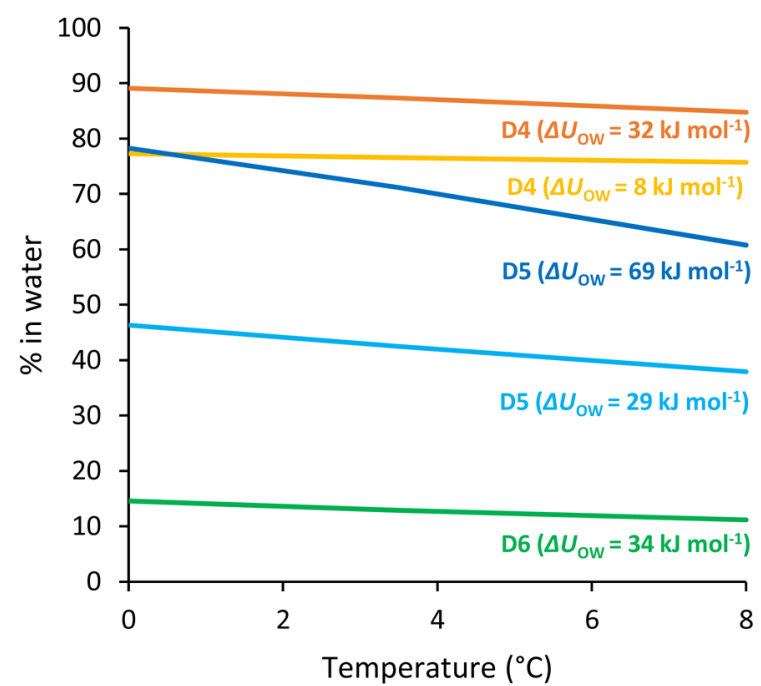

Figure 4. Predicted fractions of cVMS in the water column of Storvannet (the remaining fraction is predicted to reside in the sediments) as a function of temperature and $\Delta U_{\mathrm{OW}}$ at steady-state (SI Table S13, S14).

relatively constant for D5 and D6 (SI Table S13). Moreover, overall persistence $\left(P_{\mathrm{OV}}\right)$ was predicted to increase with increasing temperature for D5 and D6 in the absence of an ice cover. This can be explained by an increased partitioning to sediment at higher temperatures where degradation is negligible and suggests that the effect of temperature on partitioning was more important than the effect of temperature on hydrolysis.

As the value of $\Delta U_{\mathrm{OW}}$ controls the slope of the temperature dependence of $K_{\mathrm{OC}}$, a higher $\Delta U_{\mathrm{OW}}$ value implies an even more pronounced partitioning to water at low temperatures (Figure 4 , SI Figure S3) ( $P_{\mathrm{OV}}$ for D5 is lower at all temperature scenarios when using $\Delta U_{\mathrm{OW}}=68.8 \mathrm{~kJ} \mathrm{~mol}^{-1}$ compared with 29 $\mathrm{kJ} \mathrm{mol}^{-1}$ : SI Table S14). The assumption of higher $\Delta U_{\mathrm{OW}}$ values also results in higher (and more unrealistic) emission estimates derived from inverse steady state modeling $(15.7 \mathrm{~kg}$ $\mathrm{y}^{-1}$ compared with $4.7 \mathrm{~kg} \mathrm{y}^{-1}$ when $\Delta U_{\mathrm{OW}}=68.8 \mathrm{~kJ} \mathrm{~mol}^{-1}$ instead of $29 \mathrm{~kJ} \mathrm{~mol}^{-1}$ for D5 at average temperature) (SI Table S14). Similarly, it also results in predicted concentrations of D5 in water that are far above our LOQs (SI Table S14). This suggests that a high effective value of $K_{\mathrm{OC}}$ at average lake temperature would be more consistent with the observed concentrations of cVMS in Storvannet sediment. This could be achieved by using either a lower $\Delta U_{\mathrm{OW}}$ value or a higher $K_{\mathrm{OC}}$ value at reference temperature (SI Figure S3). 42,44

Cold lakes not only have low temperatures, but also seasonal ice covers. The inclusion of an ice cover in the steady-state scenarios increased the dominant importance of advection (>90\% of loss) and increased $P_{\mathrm{W}}$ and $P_{\mathrm{OV}}$ for all compounds compared to the ice-free winter scenario, due to cessation of volatilization (SI Table S13, S14). Thus, the combination of low temperatures and ice cover development may affect the persistence of cVMS in complex ways depending on the specific lake in question (and its dominant removal processes). It has been shown that the relative importance of various loss processes will vary with lake characteristics, ${ }^{18}$ and the effect of low temperatures and ice cover on cVMS behavior will hence depend on the specific lake in question, including its emission scenario. In systems with pronounced temporal variability (i.e., seasonality or intermittent emissions), this may not be captured realistically in steady-state scenarios.
3.2.3. The Impact of Dynamic Emissions. Concentrations of cVMS in sediments of Storvannet result from intermittent emissions associated with CSOs (especially during spring snowmelt). Such a nonsteady-state emission pattern should generate a higher fugacity ratio between sediment and water for most of the year, except during CSO events, than predicted under steady-state conditions with thermodynamic equilibrium or near-equilibrium conditions (SI Table S13). This implies that predicted steady-state partitioning from temperatureadjusted $K_{\mathrm{OC}}$ is not representative for Storvannet for most of the year. To test the plausibility of this hypothesis, a dynamic emission scenario was constructed based on river flows (section 2.4 ) and assuming, in the first instance, $\Delta U_{\mathrm{OW}}=7.9$ and $29 \mathrm{~kJ}$ $\mathrm{mol}^{-1}$ for D4 and D5, respectively. Dynamic predictions over a three-year period suggest that, for the assumed emission pattern, concentrations of cVMS in water are generally low $(<\mathrm{LOD})$, but periodically increase during high flow events (up to $400 \mathrm{ng} \mathrm{L}^{-1}$ for D5) (Figure 5, SI Figure S10, S11). The

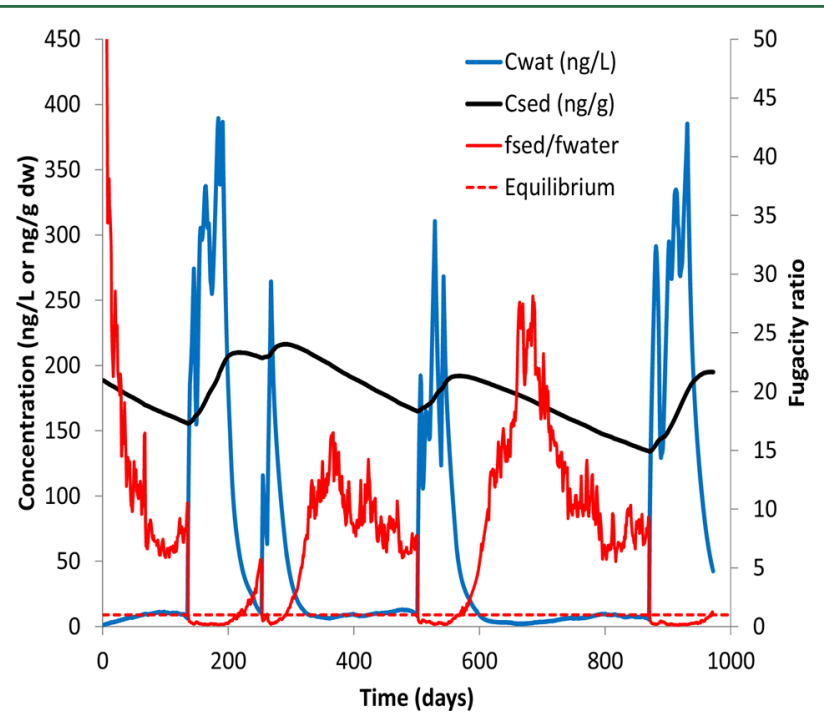

Figure 5. Predicted changes in the concentration of D5 in water (Cwat) and sediment (Csed) in Storvannet over a three-year period assuming a hypothetical intermittent emission scenario consistent with CSOs. Also shown is the fugacity ratio between sediment and water (fsed/fwater) which is $<1$ during flow events but $\gg 1$ at other times.

temporal pattern of predicted cVMS concentrations in sediment is much less variable. Concentrations decrease gradually during winter low flow periods and rise during high emission periods as near-surface sediment is replenished with contaminated material depositing out of the water column. During low flow periods, the system is far from equilibrium with high sediment:water fugacity ratios (Figure 5, SI Figure S10, S11). During periods of high flow (and high emissions), the fugacity ratio falls below 1 representing net cVMS flux from water to sediment. The relatively constant predicted concentrations in sediment over the long-term reflect the long persistence of cVMS in this compartment.

Dynamic simulations for D5 using $\Delta U_{\mathrm{OW}}=68.8 \mathrm{~kJ} \mathrm{~mol}^{-1}$, keeping all other parameters (including emissions) unchanged, resulted in similar concentrations in water, a slight increase in the sediment to water fugacity ratio between emission events, and a lower concentration in sediment (SI Figure S12). Also, the predicted concentrations in sediment decreased with time. Thus, higher emissions or more frequent $\mathrm{CSO}$ sould be 
required to maintain the measured D5 concentrations in sediments due to a higher fraction of chemical in the dissolved water phases where it is more quickly removed. These simulations suggest that a higher $\log K_{\mathrm{OC}}$ of approximately 5 or greater at temperatures relevant for Storvannet gives better agreement with the observed concentration data than a lower $\log K_{\mathrm{OC}}$. This can be achieved e.g. using a $\log K_{\mathrm{OC}}$ of 6.2 at 25 ${ }^{\circ} \mathrm{C}$ combined with $\Delta U_{\mathrm{OW}}=68.8 \mathrm{~kJ} \mathrm{~mol}^{-1}$ or a $\log K_{\mathrm{OC}}$ of 5.2 at $25{ }^{\circ} \mathrm{C}$ combined with $\Delta U_{\mathrm{OW}}=29 \mathrm{~kJ} \mathrm{~mol}^{-1}$. Other combinations with higher values of $K_{\mathrm{OC}}$ and lower values of $\Delta U_{\text {OW }}$ may also generate reasonable predicted outcomes.

Although Storvannet is not a typical high latitude lake in terms of its contamination history, it provides some interesting insights into the effect of high latitude environmental conditions on the freshwater behavior of cVMS. Particularly, it illustrates how a positive $\Delta U_{\text {OW }}$ value may result in little change in predicted persistence at lower temperatures. This contrasts with expected behavior of other pollutants in cold environments $^{59-61}$ and challenges the view that organic contaminants are more persistent in high latitude than in temperate environments. We recommend that this is taken into consideration for cVMS in both scientific and regulatory processes, and similarly for other contaminants of emerging concern that may behave differently to legacy POPs. Ignoring this could lead to erroneous conclusions regarding emerging chemicals of concern and their fate in high latitude environments. Further research should attempt to reduce the uncertainties in the temperature dependence of $K_{\mathrm{OC}}$, as well as the temperature dependence of cVMS hydrolysis. Moreover, this study illustrates the importance of considering site-specific parameters such as temperatures, water flows and emission scenarios which need to be taken into account by scientists and regulators when interpreting measurements and when extrapolating/generalizing to larger areas and regions such as the Arctic. Mass-balance models are invaluable for understanding the relative importance of transport and removal mechanisms, as well as the factors that influence them. For biota residing in the lake, the intermittent emissions and the low hydraulic retention time of Storvannet has implications for exposure to cVMS. For most of the year, the only significant source of cVMS to biota will be the sediment, even for organisms that are mainly pelagic. Hence, even if only a small fraction of the total food intake is from the sediment, this may drive exposure in the whole food web.

\section{ASSOCIATED CONTENT}

\section{S Supporting Information}

The Supporting Information is available free of charge on the ACS Publications website at DOI: 10.1021/acs.est.6b04828.

Detailed descriptions of methods and results (PDF)

\section{AUTHOR INFORMATION}

\section{Corresponding Author}

*Phone: +47 638982 98; e-mail: isk@nilu.no.

\section{ORCID ${ }^{\circ}$}

Ingjerd Sunde Krogseth: 0000-0002-6063-6655

\section{Notes}

The authors declare no competing financial interest.

\section{ACKNOWLEDGMENTS}

We thank the Research Council of Norway (project number 222259) and FRAM-High North Research Centre on Climate and the Environment, flagship "Hazardous substances-effects on ecosystems and human health" for financing the study, Hammerfest municipality and local fishermen for sampling assistance, Dow Corning Corporation for providing reference sediment material, and former Unilab Analyse AS for access to TOC-analyses and the headspace-GCMS instrument. MW benefitted from Study Leave granted by the University of Leicester.

\section{REFERENCES}

(1) Brooke, D.; Crookes, M.; Gray, D.; Robertson, S. Environmental Risk Assessment Report: Decamethylcyclopentasiloxane; Environment Agency of England and Wales: Bristol, UK, 2009.

(2) Brooke, D.; Crookes, M.; Gray, D.; Robertson, S. Environmental Risk Assessment Report: Octamethylcyclotetrasiloxane; Environment Agency of England and Wales: Bristol, UK, 2009.

(3) Brooke, D.; Crookes, M.; Gray, D.; Robertson, S. Environmental Risk Assessment Report: Dodecamethylcyclohexasiloxane; Environment Agency of England and Wales: Bristol, UK, 2009.

(4) Wang, D.-G.; Norwood, W.; Alaee, M.; Byer, J. D.; Brimble, S. Review of recent advances in research on the toxicity, detection, occurrence and fate of cyclic volatile methyl siloxanes in the environment. Chemosphere 2013, 93, 711-725.

(5) van Egmond, R.; Sparham, C.; Hastie, C.; Gore, D.; Chowdhury, $\mathrm{N}$. Monitoring and modelling of siloxanes in a sewage treatment plant in the UK. Chemosphere 2013, 93, 757-765.

(6) Wang, D.-G.; Steer, H.; Tait, T.; Williams, Z.; Pacepavicius, G.; Young, T.; Ng, T.; Smyth, S. A.; Kinsman, L.; Alaee, M. Concentrations of cyclic volatile methylsiloxanes in biosolid amended soil, influent, effluent, receiving water, and sediment of wastewater treatment plants in Canada. Chemosphere 2013, 93, 766-773.

(7) Wang, D.-G.; Aggarwal, M.; Tait, T.; Brimble, S.; Pacepavicius, G.; Kinsman, L.; Theocharides, M.; Smyth, S. A.; Alaee, M. Fate of anthropogenic cyclic volatile methylsiloxanes in a wastewater treatment plant. Water Res. 2015, 72, 209-17.

(8) European Chemicals Agency (ECHA). Member state committe (MSC) opinion on persistency and bioaccumulation of octamethylcyclotetrasiloxane (D4) EC Number: 209-136-7 CAS Number: 556-67-2 and decamethylcyclopentasiloxane (D5) EC Number: 208-764-9 CAS Number 541-02-6 according to a MSC mandate, adopted on 22 April 2015; European Chemicals Agency (ECHA): Helsinki, Finland, 2015.

(9) Committee for Risk Assessment (RAC), Committee for SocioEconomic Analysis (SEAC). Background Document to the Opinion on the Annex XV dossier proposing restrictions on Octamethylcyclotetrasiloxane (D4) and Decamethylcyclopentasiloxane (D5). ECHA/RAC/RES-O0000001412-86-97/D, EHCA/SEAC/RES-O-0000001412-86-109/ F; European Chemicals Agency (ECHA): Finland, 2016.

(10) Kaj, L.; Schlabach, M.; Andersson, J.; Cousins, A. P.; Schmidbauer, N.; Brorström-Lundén, E. Siloxanes in the Nordic Environment; Nordic Council of Ministers: Copenhagen, Denmark, 2005.

(11) Kierkegaard, A.; van Egmond, R.; McLachlan, M. S. Cyclic volatile methylsiloxane bioaccumulation in flounder and ragworm in the Humber Estuary. Environ. Sci. Technol. 2011, 45, 5936-5942.

(12) Kierkegaard, A.; Bignert, A.; McLachlan, M. S. Bioaccumulation of decamethylcyclopentasiloxane in perch in Swedish lakes. Chemosphere 2013, 93, 789-793.

(13) McGoldrick, D. J.; Letcher, R. J.; Barresi, E.; Keir, M. J.; Small, J.; Clark, M. G.; Sverko, E.; Backus, S. M. Organophosphate flame retardants and organosiloxanes in predatory freshwater fish from locations across Canada. Environ. Pollut. 2014, 193, 254-261.

(14) Warner, N. A.; Evenset, A.; Christensen, G.; Gabrielsen, G. W.; Borgå, K.; Leknes, H. Volatile siloxanes in the European Arctic: 
assessment of sources and spatial distribution. Environ. Sci. Technol. 2010, 44, 7705-7710.

(15) Warner, N. A.; Nøst, T. H.; Andrade, H.; Christensen, G. Allometric relationships to liver tissue concentrations of cyclic volatile methyl siloxanes in Atlantic cod. Environ. Pollut. 2014, 190, 109-114.

(16) Hughes, L.; Mackay, D.; Powell, D. E.; Kim, J. An updated state of the science EQC model for evaluating chemical fate in the environment: Application to D5 (decamethylcyclopentasiloxane). Chemosphere 2012, 87, 118-124.

(17) Mackay, D.; Hughes, L.; Powell, D. E.; Kim, J. An updated Quantitative Water Air Sediment Interaction (QWASI) model for evaluating chemical fate and input parameter sensitivities in aquatic systems: Application to D5 (decamethylcyclopentasiloxane) and PCB180 in two lakes. Chemosphere 2014, 111, 359-365.

(18) Whelan, M. J. Evaluating the fate and behaviour of cyclic volatile methyl siloxanes in two contrasting North American lakes using a multi-media model. Chemosphere 2013, 91, 1566-1576.

(19) Undeman, E.; Gustafsson, B.; Humborg, C.; McLachlan, M. Application of a novel modeling tool with multistressor functionality to support management of organic contaminants in the Baltic Sea. Ambio 2015, 44, 498-506.

(20) Whelan, M. J.; Breivik, K. Dynamic modelling of aquatic exposure and pelagic food chain transfer of cyclic volatile methyl siloxanes in the Inner Oslofjord. Chemosphere 2013, 93, 794-804.

(21) Xu, S.; Wania, F. Chemical fate, latitudinal distribution and longrange transport of cyclic volatile methylsiloxanes in the global environment: A modeling assessment. Chemosphere 2013, 93, 835843.

(22) Rikardsen, A. H.; Amundsen, P. A.; Bjørn, P. A.; Johansen, M. Comparison of growth, diet and food consumption of sea-run and lake-dwelling Arctic charr. J. Fish Biol. 2000, 57, 1172-1188.

(23) Christensen, G. N.; Evenset, A.; Dahl-Hansen, G.; Götsch, A. Storvatn $i$ Hammerfest kommune. Undersøkelse av miljøgifter $i$ vann, sediment og fisk, 2008; Akvaplan-niva AS: Tromsø, Norway, 2009.

(24) Mackay, D. Finding fugacity feasible. Environ. Sci. Technol. 1979, 13, 1218-1223.

(25) Mackay, D. Multimedia Environmental Models. The Fugacity Approach, 2nd ed.; Lewis publishers: Boca Raton, FL, 2001.

(26) MacLeod, M.; Scheringer, M.; McKone, T. E.; Hungerbühler, K. The state of multimedia mass-balance modeling in environmental science and decision-making. Environ. Sci. Technol. 2010, 44, 83608364.

(27) Rikardsen, A. H.; Svenning, M. A.; Klemetsen, A. The relationships between anadromy, sex ratio and parr growth of Arctic charr in a lake in North Norway. J. Fish Biol. 1997, 51, 447-461.

(28) Sparham, C.; Van Egmond, R.; O'Connor, S.; Hastie, C.; Whelan, M.; Kanda, R.; Franklin, O. Determination of decamethylcyclopentasiloxane in river water and final effluent by headspace gas chromatography/mass spectrometry. J. Chromatogr. A 2008, 1212, 124-129.

(29) Sparham, C.; van Egmond, R.; Hastie, C.; O’Connor, S.; Gore, D.; Chowdhury, N. Determination of decamethylcyclopentasiloxane in river and estuarine sediments in the UK. J. Chromatogr. A 2011, 1218, 817-823.

(30) Biedermann, M.; Fiscalini, A.; Grob, K. Large volume splitless injection with concurrent solvent recondensation: Keeping the sample in place in the hot vaporizing chamber. J. Sep. Sci. 2004, 27, 11571165.

(31) Companioni-Damas, E. Y.; Santos, F. J.; Galceran, M. T. Analysis of linear and cyclic methylsiloxanes in sewage sludges and urban soils by concurrent solvent recondensation - large volume injection - gas chromatography-mass spectrometry. J. Chromatogr. A 2012, 1268, 150-156.

(32) Companioni-Damas, E. Y.; Santos, F. J.; Galceran, M. T. Linear and cyclic methylsiloxanes in air by concurrent solvent recondensation-large volume injection-gas chromatography-mass spectrometry. Talanta 2014, 118, 245-252.

(33) Warner, N. A.; Kozerski, G.; Durham, J.; Koerner, M.; Gerhards, R.; Campbell, R.; McNett, D. A. Positive vs. false detection: A comparison of analytical methods and performance for analysis of cyclic volatile methylsiloxanes (cVMS) in environmental samples from remote regions. Chemosphere 2013, 93, 749-756.

(34) Mackay, D.; Joy, M.; Paterson, S. A quantitative water, air, sediment interaction (QWASI) fugacity model for describing the fate of chemicals in lakes. Chemosphere 1983, 12, 981-997.

(35) Breivik, K.; Bjerkeng, B.; Wania, F.; Magnusson, J.; Helland, A.; Pacyna, J. M. The Oslofjord POP Model v. 1.0. A fugacity-based nonsteady state non-equilibrium multimedia fate and transport model; OR 24/2003; NILU - Norwegian Institute for Air Research: Kjeller, Norway, 2003.

(36) Christensen, G. N.; Falk, A. H. Kildekartlegging av miljøgifter rundt Storvatn i Hammerfest - analyser fra sigevannsbrønner; Akvaplanniva AS: Tromsø, Norway, 2010.

(37) Norwegian Water Resources and Energy Directorate. NVE atlas; http://atlas.nve.no/SilverlightViewer/?Viewer=NVEAtlas.

(38) Hammerfest kommune. Hammerfest vannverk; http://www. hammerfest.no/hammerfest-vannverk.4759397-154992.html.

(39) Norwegian Meteorological Institute. eKlima; eklima.met.no.

(40) Rikardsen, A. H.; Amundsen, P. A.; Bodin, P. J. Growth and diet of anadromous Arctic charr after their return to freshwater. Ecol. Freshw. Fish 2003, 12, 74-80.

(41) Whelan, M. J.; Sanders, D.; van Egmond, R. Effect of Aldrich humic acid on water-atmosphere transfer of decamethylcyclopentasiloxane. Chemosphere 2009, 74, 1111-1116.

(42) Whelan, M. J.; van Egmond, R.; Gore, D.; Sanders, D. Dynamic multi-phase partitioning of decamethylcyclopentasiloxane (D5) in river water. Water Res. 2010, 44, 3679-3686.

(43) Kozerski, G. E.; Xu, S.; Miller, J.; Durham, J. Determination of soil-water sorption coefficients of volatile methylsiloxanes. Environ. Toxicol. Chem. 2014, 33, 1937-1945.

(44) Panagopoulos, D.; Jahnke, A.; Kierkegaard, A.; MacLeod, M. Organic carbon/water and dissolved organic carbon/water partitioning of cyclic volatile methylsiloxanes: Measurements and polyparameter linear free energy relationships. Environ. Sci. Technol. 2015, 49, 1216112168.

(45) Xu, S.; Kozerski, G.; Mackay, D. Critical review and interpretation of environmental data for volatile methylsiloxanes: partition properties. Environ. Sci. Technol. 2014, 48, 11748-11759.

(46) Xu, S.; Kropscott, B. Method for simultaneous determination of partition coefficients for cyclic volatile methylsiloxanes and dimethylsilanediol. Anal. Chem. 2012, 84, 1948-1955.

(47) Xu, S.; Kropscott, B. Evaluation of the three-phase equilibrium method for measuring temperature dependence of internally consistent partition coefficients (KOW, KOA, and KAW) for volatile methylsiloxanes and trimethylsilanol. Environ. Toxicol. Chem. 2014, 33, $2702-2710$

(48) Xu, S. H.; Kozerski, G. E. Assessment of the Fundamental Partitioning Properties of Permethylated Cyclosiloxanes; SETAC Europe: Porto, Portugal, 2007.

(49) Kierkegaard, A.; McLachlan, M. S. Determination of linear and cyclic volatile methylsiloxanes in air at a regional background site in Sweden. Atmos. Environ. 2013, 80, 322-329.

(50) Krogseth, I. S.; Kierkegaard, A.; McLachlan, M. S.; Breivik, K.; Hansen, K. M.; Schlabach, M. Occurrence and seasonality of cyclic volatile methyl siloxanes in Arctic air. Environ. Sci. Technol. 2013, 47, 502-509.

(51) Price, O. R.; Williams, R. J.; Zhang, Z.; van Egmond, R. Modelling concentrations of decamethylcyclopentasiloxane in two UK rivers using LF2000-WQX. Environ. Pollut. 2010, 158, 356-360.

(52) Borgå, K.; Fjeld, E.; Kierkegaard, A.; Løvik, J. E.; Rognerud, S.; Høgfeldt, A. S.; Bæk, K.; McLachlan, M. S. Siloxanes in Freshwater Food Webs-A Study of Three Lakes in Norway; The Norwegian Environment Agency: Oslo, Norway, 2013.

(53) Schlabach, M.; Andersen, M. S.; Green, N.; Schøyen, M.; Kaj, L. Siloxanes in the Environment of the Inner Oslofjord; Norwegian Pollution Control Authority: Oslo, Norway, 2007.

(54) Wang, D.-G.; Alaee, M.; Steer, H.; Tait, T.; Williams, Z.; Brimble, S.; Svoboda, L.; Barresi, E.; DeJong, M.; Schachtschneider, J.; 
Kaminski, E.; Norwood, W.; Sverko, E. Determination of cyclic volatile methylsiloxanes in water, sediment, soil, biota, and biosolid using large-volume injection-gas chromatography-mass spectrometry. Chemosphere 2013, 93, 741-748.

(55) Companioni-Damas, E. Y.; Santos, F. J.; Galceran, M. T. Analysis of linear and cyclic methylsiloxanes in water by headspacesolid phase microextraction and gas chromatography-mass spectrometry. Talanta 2012, 89, 63-69.

(56) Powell, D. E.; Woodburn, K. B.; Drotar, K. D.; Durham, J.; Huff, D. W. Trophic Dilution of Cyclic Volatile Methylsiloxane (cVMS) Materials in a Temperate Freshwater Lake; HES study no. 10771-108; Internal report conducted for Centre Européen des Silicones; Dow Corning Corporation: Auburn, MI, 2009.

(57) Powell, D. E.; Durham, J.; Huff, D. W.; Böhmer, T.; Gerhards, R.; Koerner, M. Bioaccumulation and Trophic Transfer of Cyclic Volatile Methylsiloxane (cVMS) Materials in the Aquatic Marine Food Webs of the Inner and outer Oslofjord, Norway, HES study no. 11060-108; Internal report conducted for Centre Européen des Silicones; Dow Corning Corporation, Auburn, MI, 2010.

(58) Schenker, U.; MacLeod, M.; Scheringer, M.; Hungerbühler, K. Improving data quality for environmental fate models: A least-squares adjustment procedure for harmonizing physicochemical properties of organic compounds. Environ. Sci. Technol. 2005, 39, 8434-8441.

(59) Wania, F.; Mackay, D. Tracking the distribution of persistent organic pollutants. Environ. Sci. Technol. 1996, 30, A390-A396.

(60) Webster, E.; Mackay, D.; Wania, F. Evaluating environmental persistence. Environ. Toxicol. Chem. 1998, 17, 2148-2158.

(61) Sinkkonen, S.; Paasivirta, J. Degradation half-life times of PCDDs, PCDFs and PCBs for environmental fate modeling. Chemosphere 2000, 40, 943-949. 